\title{
Immunohistochemical Markers for Schwannomas, Neurofibromas and Malignant Peripheral Nerve Sheath Tumors-What Can the Recent Literature Tell Us?
}

\section{Marcadores imuno-histoquímicos para schwannomas, neurofibromas e tumores malignos da bainha do nervo periférico-o que a literatura recente pode nos dizer?}

\author{
José Fernando Guedes-Corrêa ${ }^{1}$ Rodrigo Salvador V. Cardoso ${ }^{1}$ \\ 1 Division of Neurosurgery, Hospital Universitário Gaffrée e Guinle, \\ Rio de Janeiro, RJ, Brazil \\ Arq Bras Neurocir 2018;37:105-112. \\ Address for correspondence Rodrigo Salvador Cardoso, Clinical \\ Fellow, Divisão de Neurocirurgia, Hospital Universitário Gaffrée e \\ Guinle, Rua Jardim Botânico, 700, Sala 407, Jardim Botânico, Rio de \\ Janeiro, RJ, 22461-000, Brazil (e-mail: rodrigosalvadorvc@gmail.com).
}

\begin{abstract}
Keywords

- immunohistochemistry

- biomarker

- nerve sheath neoplasm(s)

- schwannoma

- neurofibroma

- malignant peripheral nerve sheath tumor

Introduction Schwannomas and neurofibromas are the two most common benign neoplasms of the peripheral nerve sheath, and although they are generally easy to distinguish, in some cases, they can closely resemble one another. Furthermore, malignant peripheral nerve sheath tumors (MPNSTs), another example of peripheral nerve sheath neoplasm, may likewise constitute, due to their morphology and lack of specific immunohistochemical markers, a challenging diagnostic.

Objective To bring attention to new and promising biomarkers for schwannomas, neurofibromas and MPNSTs and to outline, based on the recent literature, a immunohistochemical profile for each neoplasm at hand, as well as to emphasize the need for further studies that could help us understand their diagnostic potential and disrupt our dependence of limited and nonspecific biomarkers.

Methods An overview of the recent literature published in English on both the classical promising immunohistochemical markers of schwannomas, neurofibromas and MPNSTs was performed. We discarded case reports.

Conclusions There is still a lack of specific biomarkers for peripheral nerve tumors. However, plenty of new immunohistochemical markers have been coming to light with presumed higher specificity and more diverse helpful uses than the classical ones. For example, Sox10 is a good biomarker for differentiating schwannomas and neurofibromas from sarcomas, calretinin schwannomas from neurofibromas, TLE1 and HMGA2 MPNSTs from sarcomas, and nestin, EGFR, p16 and $\mathrm{K}_{\mathrm{i}}-67$ MPNSTs from different types of schwannomas and neurofibromas. There is still need for further studies; however, the potential of some of these promising markers, among others, should not be disregarded.
\end{abstract}

received

March 29, 2018

accepted

June 5,2018
DOI https://doi.org/

10.1055/s-0038-1667180.

ISSN 0103-5355.
Copyright $\odot 2018$ by Thieme Revinter

Publicações Ltda, Rio de Janeiro, Brazil

License terms

(c) $(1) \$$ 


\section{Resumo}

\section{Palavras-chave}

- imuno-histoquímica

- biomarcador

- tumor(es) do sistema nervoso periférico

- schwannoma

- neurofibroma

- tumor maligno da bainha do nervo
Introdução Schwannomas e neurofibromas são as duas neoplasias benignas mais comuns a acometer o tecido nervoso periférico, e apesar de geralmente serem facilmente distinguíveis, em alguns casos, elas podem ser muito semelhantes. Além disso, os tumores malignos da bainha dos nervos periféricos (TMBNPs), outro exemplo de neoplasia da bainha do nervo periférico, podem da mesma forma constituir, pela sua morfologia e falta de marcadores imuno-histoquímicos específicos, um diagnóstico desafiador.

Objetivo Chamar a atenção para novos e promissores biomarcadores para schwannomas, neurofibromas e TMBNPs e delinear, a partir da literatura atual, um perfil imuno-histoquímico para cada neoplasia em questão, além de enfatizar a necessidade de futuros estudos que possam elucidar-nos acerca de seu potencial diagnóstico e, por ventura, romper nossa dependência de biomarcadores inespecíficos e limitados.

Método Foi feita uma revisão da literatura recente incluindo artigos em língua inglesa sobre os marcadores imunohistoquímicos clássicos e os promissores para schwannomas, neurofibromas e TMBNPs. Descartamos relatos de caso.

Conclusão Ainda há uma falta de biomarcadores específicos para as neoplasias acima. Contudo, vários novos marcadores imuno-histoquímicos têm surgido, e com futuros estudos poderemos talvez definir biomarcadores específicos e indispensáveis para os casos desafiadores de neurofibromas, schwannomas e TMBNPs. Por exemplo, o Sox10 é um bom biomarcador para diferenciar schwannomas e neurofibromas de sarcomas; a calretinina é um bom marcador para diferenciar schwannomas de neurofibromas; os biomarcadores TLE1 e HMGA2 podem ajudar a diferenciar TMBNPs de sarcomas, e a nestina, o receptor do fator de crescimento epidérmico (EGFR), o gene p16 e a proteína $\mathrm{K}_{\mathrm{i}}-67$ podem diferenciar TMBNPs de diferentes tipos de schwannomas e neurofibromas. Ainda há necessidade de novos estudos; contudo, o potencial de alguns desses marcadores, dentre outros, não deveria ser negligenciado.

\section{Introduction}

Schwannoma and neurofibroma are the two most frequent benign tumors that arise from the peripheral nerves. ${ }^{1}$

Schwannomas are benign neoplasms usually encapsulated and composed exclusively of immature Schwann cells that arise from the peripheral nerve sheath, ${ }^{2}$ whereas neurofibromas, the most frequent benign tumors in neurofibromatosis type 1 (NF1), contain, besides malignant peripheral nerve sheath tumor (MPNST), proliferating Schwann cells and other local supporting elements of the nerve fibers, including perineurial cells, fibroblasts, axons, blood vessels and infiltration of mast cells. ${ }^{1,3,4}$

Although these tumors are generally easy to distinguish by standard light microscopy, in some cases, they might closely resemble one another. ${ }^{1}$

On the other hand, MPNSTs are malignant neoplasms with nerve sheath differentiation that originate from the peripheral nerve sheath or the adjacent extraneural soft tissue. Due to their morphologic heterogeneity and lack of specific immunohistochemical or molecular criteria, the diagnosis of MPNST is often challenging, including various sarcomas and benign peripheral nerve sheath tumors, such as cellular schwannoma or atypical/cellular neurofibroma. ${ }^{1,4-7}$
Besides the well-sedimented lack of specific markers for peripheral nerve sheath tumors, ${ }^{4,6-9}$ they also share some biomarkers, which makes the diagnosis even harder. ${ }^{1}$ Thus, it is necessary to outline the antigen patterns for each in order to reduce the risk for misdiagnosis, ${ }^{10}$ when the microscopy is not enough. This process must be followed not only for schwannomas, neurofibromas and MPNSTs, but also between each of these three and their related possible differential diagnoses.

Immunohistochemistry is an ordinary tool in the diagnosis of soft tissue tumors. It is a valuable resource when a careful assessment of histopathology and formulation of differential diagnosis are inconclusive and there still are differential diagnostic possibilities. Conversely, the use of diagnostic immunohistochemistry regardless of the histological context frequently results in serious errors and is strongly discouraged. ${ }^{11}$

Schwannomas, neurofibromas and MPNSTs are soft tissue tumors and often have histopathological differential diagnosis with other soft tissue tumors, ${ }^{6,11}$ with which they share multispecific markers and antigenic complexities of many tumor types ${ }^{11}$ and hence, there is a need of new and specific biomarkers for these cases.

In this review we will briefly expose the common expected histology of the schwannoma, neurofibroma and MPNST, as well as their variants, followed by the main differential diagnosis 
in each situation. Then, a discussion about the well-established and recent promising markers will be built to set a layout (-Table 1) of alternative and more embracing immunohistochemistry to avoid misdiagnosis and draft more precisely therapeutic schemes and prognosis.

\section{Method}

This article aims to outline updated useful biomarkers for the most common benign peripheral nerve tumors, schwannoma and neurofibroma, ${ }^{1}$ as well as for MPNSTs. For such, we looked up through the Google Scholar and the PubMed Central (PMC) research platforms for articles published in English during the latter 15 years. We resorted to the Boolean Operators, always

Table 1 Useful immunophenotypic features in the differential diagnosis of schwannoma, neurofibroma and malignant peripheral nerve sheath tumor

\begin{tabular}{|c|c|c|c|}
\hline IHC Marker & Schwannoma & Neurofibroma & MPNST \\
\hline $\mathrm{S} 100$ & +++ & ++ & $\begin{array}{l}+/+++ \text { (only in } \\
\text { the epithelioid } \\
\text { MPNST) }\end{array}$ \\
\hline CD34 & $\begin{array}{l}+++ \\
\text { (Antoni } \\
\text { A areas) }\end{array}$ & +++ & $+1++$ \\
\hline Sox10 & +++ & +++ & $+1++$ \\
\hline EMA & + & $0 /+$ & $\begin{array}{l}0 \text { (except for } \\
\text { MPNST with } \\
\text { perineurial } \\
\text { differentiation) }\end{array}$ \\
\hline Calretinin & +++ & + & \\
\hline GFAP & + & + & + \\
\hline \multicolumn{4}{|l|}{ NSE } \\
\hline Leu7 & $0 /+$ & $0 /+$ & \\
\hline GAP43 & $0 /+$ & $0 /+$ & \\
\hline \multicolumn{4}{|l|}{ RTK/AXL } \\
\hline TLE1 & +++ & $+1++$ & $+1++$ \\
\hline Podoplanin & $\begin{array}{l}++ \\
\text { (Antoni A) }\end{array}$ & $\begin{array}{l}0 \text { (except for } \\
\text { atypical) }\end{array}$ & $+1++$ \\
\hline CD56/PGP9.5 & ++ & ++ & ++ \\
\hline Nestin & $0 /+$ & ++ & ++ \\
\hline HMGA2 & & & $+1++$ \\
\hline EGFR & 0 & & $+1++$ \\
\hline p16 & $+1++$ & $0 /+$ & $0 /+$ \\
\hline Neurofibromin & & & $\begin{array}{l}0 \text { (except for a } \\
\text { few low-grade } \\
\text { cases of MPNST) }\end{array}$ \\
\hline $\mathrm{K}_{\mathrm{i}-67}$ & $+1++$ & & $++1+++$ \\
\hline P57NTR & + & & ++ \\
\hline Sox2 & ++ & & ++ \\
\hline
\end{tabular}

Abbreviations: + , weak expression of the marker; ++ , moderate expression of the marker; +++ , strong expression of the marker; 0 , no expression of the marker; Blank space, no information contemplated by this review of the marker; EGFR, epidermal growth factor receptor; EMA, epithelial membrane antigen; GAP43, growth associated protein 43; GFAP, glial fibrillary acidic protein; HMGA2 high mobility group AT-hook 2; IHC, NSE, neuron-specific enolase; MPNST, malignant peripheral nerve sheath tumor; RTK, receptor tyrosine kinases; TLE1, transducin-like enhancer of split 1. using the terms Schwannoma, Neurofibroma, Malignant Peripheral Nerve Sheath Tumor or MPNST with the words Marker, Biomarker, Immunohistochemistry or immunohistochemical, as well as sorted the results by relevance. The articles which bring well consolidated biomarkers in the literature, recent alternative biomarkers with good results so far, or useful discussion about the pathology of the studied tumors were contemplated. Case reports were discarded. In the end, 25 articles published in the last 15 years were selected.

\section{Discussion}

\section{Schwannoma (-Figs. 1 and 2)}

Schwannomas are benign neoplasms that arise from the Schwann cells of the peripheral nerve sheath. They are well circumscribed masses with a variable admixture of compact spindle-cell areas with nuclear palisading and Verocay bodies (Antoni A), and reticular paucicellular areas (Antoni B). 1,6,12 Neurofibromatosis type 2 (NF2) and schwannomatosis are genetically distinct disorders that are related to predisposition of developing nerve sheath tumors, mainly schwannomas. ${ }^{8}$

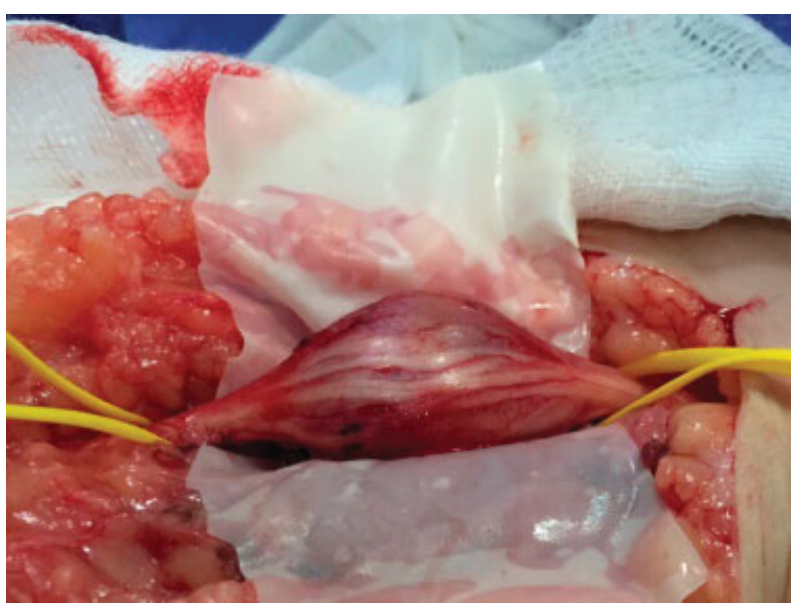

Fig. 1 Intraoperative photograph of a schwannoma of the left fibular nerve before resection. The patient is a 42-year-old non-neurofibromatosis male.

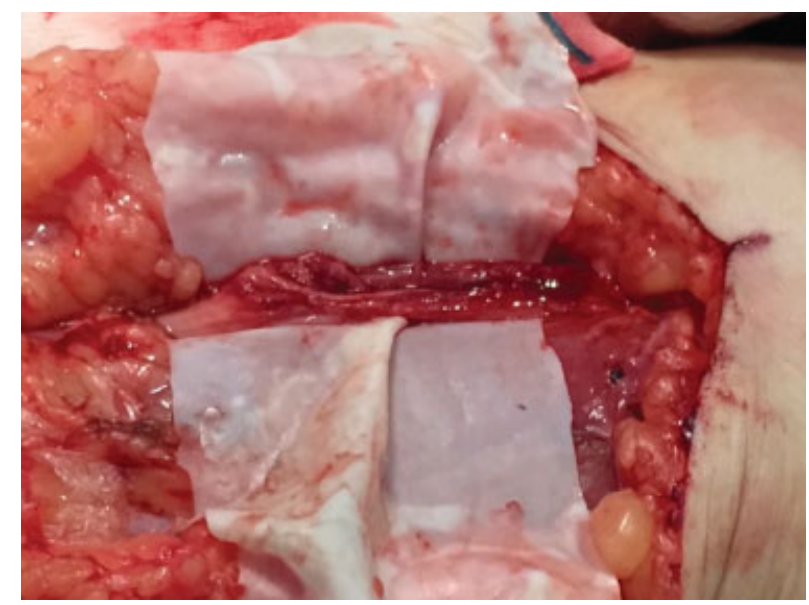

Fig. 2 Intraoperative photograph of the left fibular nerve after resection. Same patient of $\boldsymbol{-}$ Fig. $\mathbf{1}$. 
In the NF2 syndrome (1:33.000), there are alterations in the NF2 gene coding for the Merlin tumor suppressor protein that cause all tumors in the syndrome. ${ }^{2,8,13}$ Neurofibromatosis type 2 patients mainly suffer from bilateral vestibular schwannomas, meningiomas, gliomas and peripheral schwannomas. ${ }^{8,14}$

Schwannomas rarely suffer malignant degeneration and when they do, they turn into epithelioid MPNSTs, which have a strong diffuse expression of $\mathrm{S} 100 ., 6$

On the other hand, in the schwannomatosis, (recently linked to mutations in the SMARCB1 tumor suppressor gene) schwannomas are the only tumor entity observed. ${ }^{8}$

Cellular schwannoma is a variant of schwannoma composed basically of compact, fascicular growth pattern, proliferating Schwan cells with variable hyperchromasia and pleomorphism and absence of Verocay bodies. ${ }^{5,6,12}$ Because of its high cellularity, fascicular growth proliferation and increased mitotic activity, and occasionally more aggressive behavior, the cellular schwannoma can be a differential diagnosis of spindled (regular) MPNST. Besides, the cellular schwannoma presents morphologic similarities with fibrosarcoma, leiomyosarcoma, and synovial sarcoma, particularly in cases with monophasic histology or in needle biopsy specimens ${ }^{5,6,15}$

There is a rare variant of schwannoma, the melanotic schwannoma, whose histology is composed of melaninproducing cells with ultrastructural features of Schwann cells. Its immunohistochemistry is strongly positive for S100, Leu-7, HMB-45, Melan-A and vimentin. ${ }^{16}$

\section{Neurofibroma (-Figs. 3, 4, 5 and 6)}

Neurofibromas are a benign peripheral nerve sheath tumor, whose primary neoplasticcellular components are the Schwann cells, but they also have nonneoplastic peripheral nerve components, such as fibroblasts CD34 $+, 3,4,6,8,10,11,17$ perineurial cells, blood vessels, axons and mast cells. ${ }^{1,3,4} \mathrm{~A}$ total of $10 \%$ of neurofibromas are associated with neurofibromatosis $1 .{ }^{6}$

Neurofibromatosis 1 (NF1) is the most common genetic disorder of the nervous system, affecting 1 out of 3,500 new-

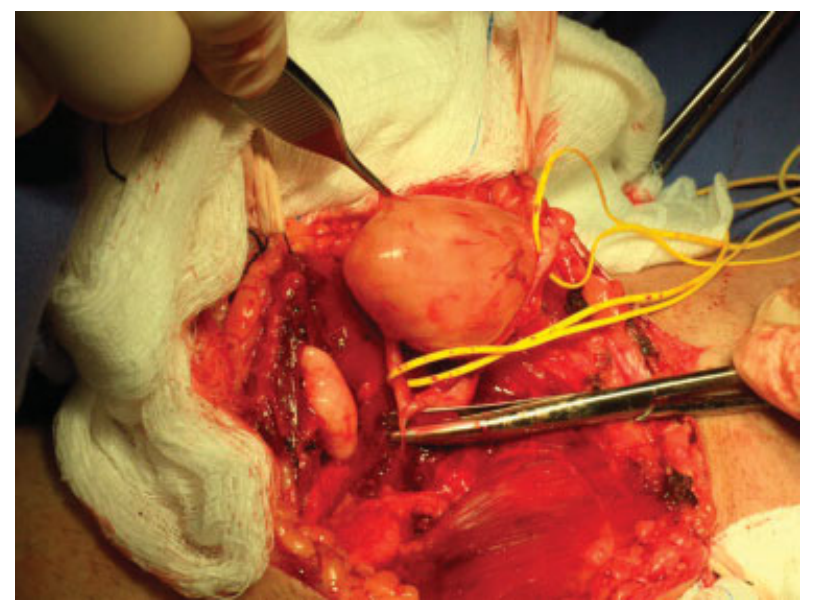

Fig. 3 Intraoperative photograph of a plexiform neurofibroma of the right tibial nerve before resection. The patient is a 34 -year-old NF-1male.

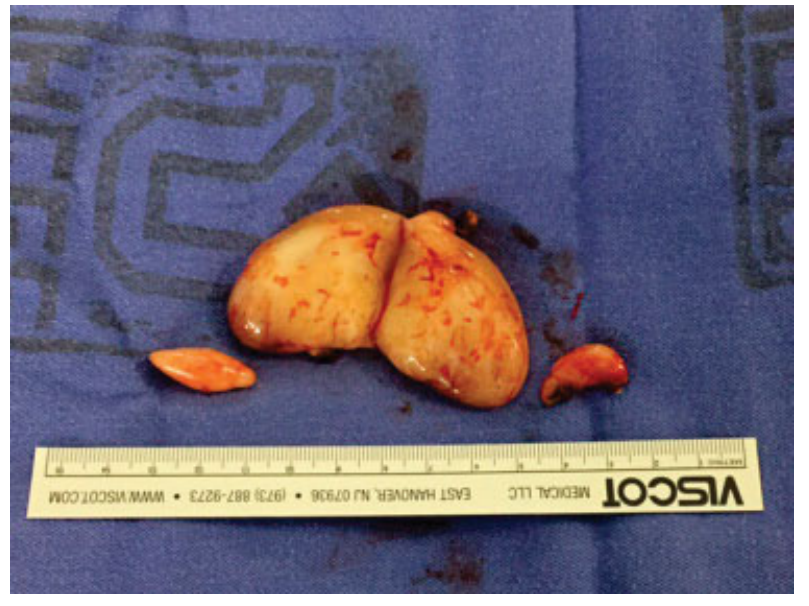

Fig. 4 Surgical specimen of a plexiform neurofibroma. Same patient of - Fig. 3.

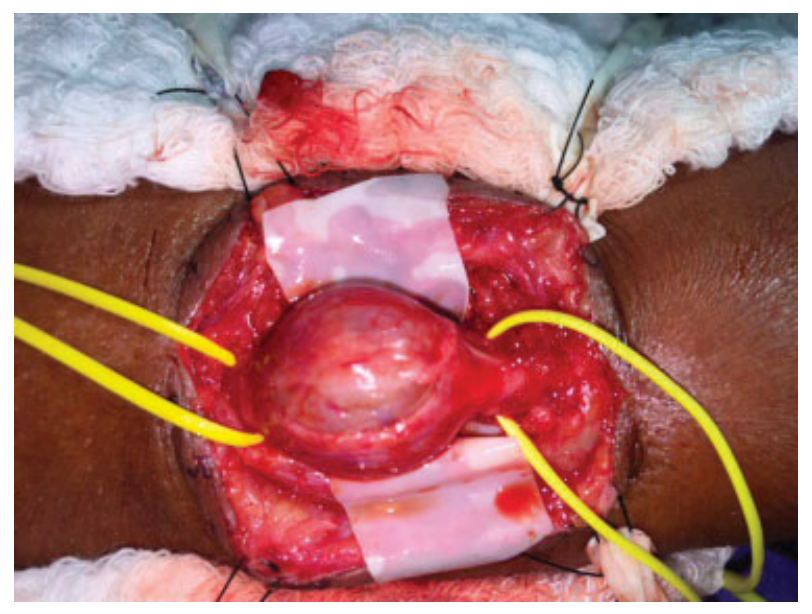

Fig. 5 Intraoperative photograph of a neurofibroma of the left sciatic nerve before resection. The patient is a 56-year-old non-neurofibromatosis female.

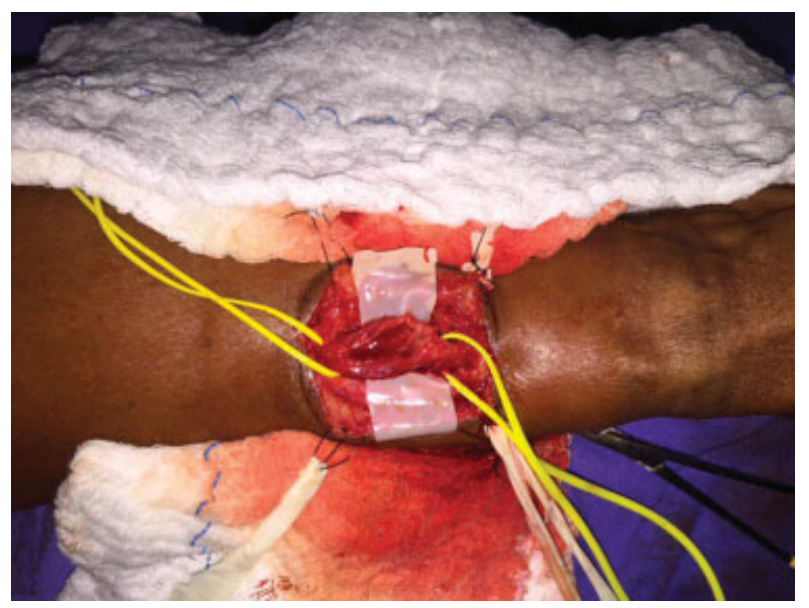

Fig. 6 Intraoperative photograph of the left sciatic nerve after resection. Same patient of $\mathbf{- F i g .} \mathbf{5}$. 
borns worldwide. ${ }^{3,18,19}$ Neurofibromatosis 1 is an autosomal dominant tumor suppressor disorder ${ }^{8,15}$ of the Ras signal transduction pathway, ${ }^{3,18}$ in which the loss of Schwann cells leads to a cascade of interactions with the neighboring cells in the microenvironment and additional cell autonomous modifications, resulting in the formation of multiple neurofibromas. ${ }^{3}$

There are three specific clinicopathologic subtypes of neurofibromas based on architectural growth pattern: localized, diffuse and plexiform. ${ }^{6}$

The two localized types of neurofibroma are the localized cutaneous neurofibromas (LCNs), or dermal neurofibroma, and the localized intraneural neurofibromas (LINs). The LCNs are the most common subtype, occurring sporadically in almost all cases, and virtually in all NF1 individuals, primarily around puberty. They consist of an intracutaneous relatively well-circumscribed nodule that grows near the budding of the nerve. The LINs are similar to the LCNs at the structural and citollogic level, but instead of the skin, they involve the nerve, and can also arise in a major nerve, typically causing a fusiform expansion of the nerve trunk. $3,4,6,8,19,20$

The diffuse neurofibroma (DFN) consists of a plaque-like elevation of the skin, usually in the head and neck region, that spreads through the subcutaneous tissue. Despite its infiltrative growth, it rarely suffers malignant degeneration. 6,20

Conversely, the plexiform neurofibroma (PXN) has a potential of 5 to $13 \%$ for malignant transformation and is practically pathognomonic of NF1. Actually, NF1 patients have a 25 to $50 \%$ chance of developing PXN. The PXN is a variant of neurofibroma that involves numerous adjacent nerve fascicles or multiple components of a nerve plexus. ${ }^{3,4,6,18,19}$

Still, there is the massive soft-tissue neurofibroma (MSTN), a very rare type of PXN often associated to NF1, which is characterized by large size, infiltration of soft tissue and skeletal muscle, frequently involving large anatomical regions. When under the microscopy light, it demonstrates the presence of cellular component. Despite its aggressive appearance, the MSTN hardly suffers malignant degeneration., 6

There are two variants of neurofibroma with unusual features, the atypical neurofibroma, with degenerative cytological atypia, and the cellular neurofibroma, with increased cellularity. They are differential diagnoses of MPNST, mainly the low-grade examples, but while the cellular neurofibroma lacks the cytological atypia, the atypical neurofibroma lacks increased cellularity or mitotic activity, and both presents lower mitotic figures than MPNST. Still, Naber et al write about the hypothesis that the atypical neurofibroma is actually a transition between a neurofibroma and a MPNST. ${ }^{8}$

There are many different possible differential diagnoses for neurofibroma, including schwannoma, nerve sheath myxoma, neurothekeoma, ganglioneuroma and traumatic neuroma as well as variety of non-nerve sheath tumors, in particular dermatofibrosarcoma protuberans (DFSP) and desmoplastic malignant melanoma. ${ }^{6}$

\section{MPNST (-Fig. 7)}

Malignant peripheral nerve sheath tumors (MPNSTs) are neural crest-malignant neoplasms with nerve sheath differ-

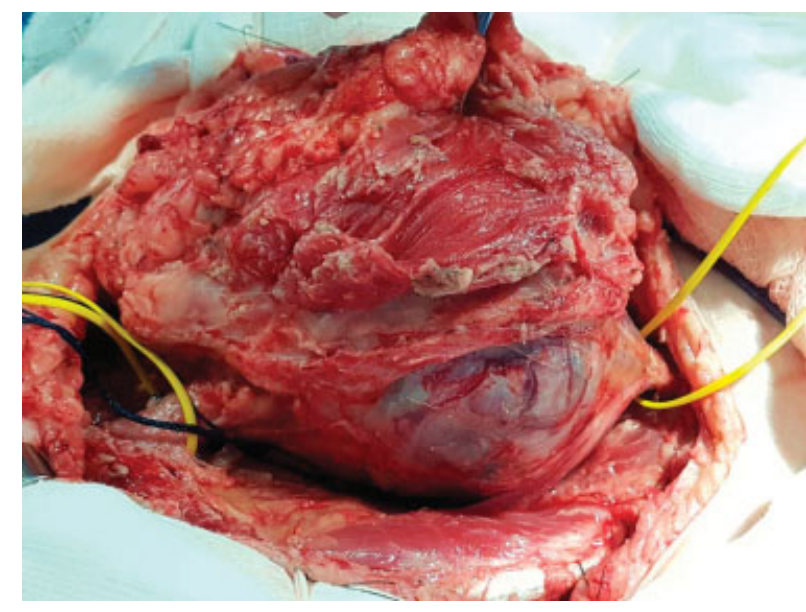

Fig. 7 Intraoperative photograph of a MPNST of the right femoral nerve. The patient is a 16-year-old non-neurofibromatosis female.

entiation, which arise from the peripheral nerve sheath or adjacent extraneural soft tissue. ${ }^{5,9,15,21}$ Due to their morphologic heterogeneity and lack of specific immunohistochemical or molecular criteria, the diagnosis of MPNSTs is often challeging. ${ }^{4}$ They arise most frequently in the proximal segments of the extremities, in the major nerve trunks (such as the sciatic nerve) followed by the trunk, head and neck. ${ }^{4}$ And 50 to $66 \%$ of the MPNSTs arise from neurofibromas, mostly of PXNs. ${ }^{7}$

The MPNST is a tumor derived from the Schwann cells or pluripotent cells of the neural crest. It displays a heterogenous cellular morphology (including spindle, epithelioid, pleomorphic or small round cells). ${ }^{8}$ Generally, the MPNST presents alternating areas of hyper or hypo cellularity or a diffuse growth pattern of spindle cells. ${ }^{7,15}$ The histologic features of the MPNST are frequently, but not specifically, fascicles; neuroD whorls; palisades or rosette-like arrangements; perineurial/intraneural spread, when associated with nerve perivascular hypercellularity; subendothelial infiltration of tumor cells; hemorrhage, and necrosis areas. ${ }^{4-6}$

There is a rare subtype of MPNST, the epithelioid MPNST, that derives more often from a preexisting schwannoma, which has suffered a malignant degeneration. ${ }^{4,6}$ In the epithelioid subtype, heterologous differentiation is observed in $15 \%$ of the MPNSTs, and it includes rhabdomyoblasts, cartilaginous and osseous components, or less commonly, smooth muscle, glandular (often with a neuroendocrine foci) or liposarcomatous components, ${ }^{7}$ particularly in patients with NF1. ${ }^{6}$ However, there is a certain controversy regarding the frequency of the rhabdomyosarcomatous differentiation; while Rodriguez et al state that it is the less frequent, ${ }^{6}$ Guo et al describe it as the most common one. ${ }^{7}$

The differential diagnosis is extensive, including benign peripheral nerve sheath tumors and various sarcomas, ${ }^{5}$ such as atypical and cellular neurofibroma, cellular schwannoma, synovial sarcoma, fibrosarcoma, rhabdomyosarcoma, leiomyosarcoma, dedifferentiated liposarcoma, clear cell sarcoma or ossifying fibromyxoid tumor of soft parts. ${ }^{6}$

\section{S100}

Although S100 is considered important to separate neoplasms with neural crest origin from the non-neural ones, ${ }^{1}$ 
it is a well-known non-specific immunohistochemical marker, as S100 is also expressed for non-neural and non-melanocytic sarcomas, such as synovial sarcoma (15\%), Ewing sarcoma (21\%), rhabdomyosarcoma (24\%), chondromyosarcoma (75\%) and extraskeletal myxoid chondrosarcoma (45\%), according to Karamchandani et al. ${ }^{15}$ The immunohistochemical staining for S-100 protein is more uniform and pronounced in schwannomas than in neurofibromas, ${ }^{1}$ whereby MPNST has a scattered expression of S100, seen in only 50 to $60 \%$ of the cases, and the majority of high-grade examples are negative. ${ }^{4,7,9,10}$ Thus, when there is a diffuse expression of S100 in a suspect MPNST sample, it suggests melanoma or cellular schwannoma, ${ }^{4}$ except for the epithelioid MPNST, which expresses diffuse S100. ${ }^{4,6}$ In this case, the differential diagnoses would be melanoma, clear cell sarcoma, epithelioid sarcoma and carcinoma. The absence of melanocytic markers, such as MelanA or HMB45, helps to discard melanoma and clear cell sarcoma, while the lack of low weight cytokeratin expression distinguishes epithelioid MPNST from epithelioid sarcoma and carcinoma. ${ }^{6}$

Ultimately, when cellular schwannoma assumes a more aggressive behavior, it can mimic MPNST. In this situation, the usage of $\mathrm{S} 100$ immunohistochemistry is crucial, as cellular schwannoma usually expresses strong diffuse S100, while MPNST rarely does. ${ }^{6}$

\section{CD34}

The transmembrane phosphoglycoprotein CD34 is ubiquitously expressed in the fibroblasts of all subtypes of neurofibromas, ${ }^{3,4,6,8,10,11,17}$ and in the Antoni A areas (compact areas) of the schwannomas. ${ }^{8}$

The MPNST, on the other hand, has a weak to medium intensity of expression of the protein, and apparently has a kind of inverse expression relation with podoplanin: when CD34 is highly expressed in MPNST the, the expression of podoplanin is weak and vice versa. ${ }^{8}$

Furthermore, CD34 is also expressed in various types of tumors, such as fibroblastic, myofibroblastic, fibrohistiocytic, vascular, neural, adipocytic, smooth muscle, melanocytic and epithelial lesions. ${ }^{4}$

Therefore, CD34 may not be a good biomarker for differentiating peripheral nerve benign lesions, and these from other lesions.

\section{Sox10}

Sox10 is useful to distinguish nerve sheath neoplasms from mesenchymal tumors, given the fact that the marker is rarely seen in non-schwannian or non-melanocytic tumors. 4,6,9,10,20,22 Sox10 has been considered a specific marker for schwannomas and neurofibromas ${ }^{9}$ and, it assists in the differentiation, in the intracranial space, of schwannomas and neurofibromas from meningioma, which expresses 20 to $30 \%$ S-100 protein, or gastrointestinal (GI) schwannomas from GI stromal tumors (that are occasionally S100-protein positive). Still, Karamchandani et al suggest that Sox10 is a useful marker for differentiating cellular schwannoma from fibrosarcoma, leiomyosarcoma, and synovial sarcoma. ${ }^{15}$ However, Sox10 is not a reasonable biomarker for MPNST, as less than half of MPNSTs express Sox10, which corresponds to entrapped or residual Schwann cells , and the high-grade MPNST examples are nearly all S100 negative. $^{10,20}$ Although Sox10 expression is also not exclusive of neural-crest tumors, ${ }^{9,10}$ it is pointed by several authors to be a more specific marker than S100., ${ }^{9,10}$ Moreover, it is suggested that Sox10 is used in combination with S100 when diagnosing MPNST, though even using both, there is a non-staining chance. ${ }^{9,10,20}$ Thus, the study and, hence, a set of a immunohistochemical identities are crucial to avoid misdiagnosis of neural crest tumors, mainly the MPNSTs.

\section{EMA}

Epithelial membrane antigen (EMA) is normally expressed in perineurial cells; therefore, it is positive stained in perineuriomas and MPNST with perineurial differentiation, but negative in schwannomas, neurofibromas or other types of MPNST. ${ }^{1,6,11,12}$

\section{Calretinin}

Although neurofibromas and schwannomas are generally easy to distinguish by standard light microscopy, when the schwannoma does not display the characteristic palisading nucleus, and it consists only (or mostly) of Antoni B areas, it can be hard to differentiate it from a neurofibroma.

Furthermore, as S-100 might not reliably distinguish these two neoplasms, calretinin is a good alternative. Samson et al have shown that whereas the schwannoma generally presents a positive staining of calretinin, with a strong staining, neurofibromas rarely stain, and when they do, it is a week staining. ${ }^{1}$ Therefore, calretinin is suggested to be a promising immunohistochemical tool for the differentiation between schwannomas and neurofibromas.

\section{GFAP, Neuron-specific Enolase, Leu-7 and GAP43}

Neuron-specific enolase (NSE) is a nonspecific biomarker supportive of nerve sheath differentiation. ${ }^{4}$ Schwannoma and neurofibroma normally do not, but occasionally can, present Leu-7 and the glial fibrillary acidic protein (GFAP). ${ }^{4,20,22}$ Le LQ et al stained Schwann cells of mouse plexiform neurofibroma with anti-growth associated protein 43 (GAP43), suggesting that in can be used in the immunohistochemical diagnosis of human neurofibromas. ${ }^{3}$

\section{RTK and AXL}

Receptor tyrosine kinase (RTKs) is a receptor expressed on the cellular membrane of neurofibromas and MPNSTs, and its exterior portion is called AXL, whose ligand is the GAS6. Johansson et al have shown that MPNST and neurofibromas, the plexiform and nodular subtypes as well as the dermal subtype, related to NF1 or not, may express increased AXL protein on their surface. Furthermore, they suggest that elevated levels of soluble AXL in the plasma (sAXL) can be detected in the presence of PXN and MPNST, as well as higher numbers of dermal neurofibromas are followed by higher levels of sAXL. Therefore, according to the latter data, SAXL could be used as a burden marker for neurofibroma. ${ }^{19}$ However, AXL is not exclusively expressed by neurofibromas and MPNST, thus, it is more a burden marker, than a diagnostic tool. ${ }^{19}$ 


\section{TLE1}

Transducin-like enhancer of split 1 (TLE1) is commonly expressed by peripheral nerve sheath tumors, including $100 \%$ of schwannomas, $33 \%$ of neurofibromas, and (in a more variable and weaker way) $30 \%$ of MPNST. ${ }^{4,6}$ Therewithal, TLE1 typically has a strong diffuse expression in synovial sarcoma. ${ }^{3,6}$ Thus, the difference between the conformation and intensity of the TLE1 expression in the MPNST and synovial sarcoma could be a discriminatory marker. ${ }^{3,4,6}$

\section{Podoplanin}

Podoplanin is a mucin-type transmembrane glycoprotein, expressed in various human cell types as well as in various tumors, such as hemangioblastomas, tissue of testis, germ cell tumors, ovarian serous carcinomas and squamous cell carcinomas. It has been associated with invasion potential of adjacent tissue, and hence, podoplanin is highly expressed in the invasive front of the MPNST. The glycoprotein is negative for dermal and plexiform neurofibromas, except for the perineurial cells, and positive in the compact area of atypical neurofibroma. Podoplanin is also positive in Antoni A (cellular) areas, but not in the Antoni B (reticular) areas of the schwannomas. Moreover, the difference between the staining pattern of schwannomatosis and NF2-associated tumors, and vestibular schwannoma tumors was not statically relevant. ${ }^{6,8}$

\section{CD56 and PGP 9.5}

CD56 and PGP 9.5 are sensitive biomarkers for peripheral nerve sheath tumors, like schwannomas and neurofibromas; thereby, they could be used as trial markers. However, their expression is not specific for MPNST. ${ }^{7,23}$

\section{Nestin}

Nestin, an intermediate filament protein expressed in neuroectodermal stem cells, ${ }^{4,7}$ has shown higher sensitivity for MPNST, ${ }^{7}$ with more extensive pattern with cytoplasmatic staining than other neural markers ${ }^{4}$ (such as CD56, PGP 9.5 or S100), whereas with weak or no expression in benign nerve sheath tumors and other sarcomas. ${ }^{4,7}$ On the other hand, Shimada et al found similar expression of nestin in rhabdomyosarcoma, leiomyosarcoma and desmoplastic melanoma. ${ }^{24}$ And hence, nestin, if in combination with other markers, may be an useful marker in the diagnosis of MPNST.

\section{HMGA2}

The high mobility group AT-hook 2 (HMGA2) has been considered as a specific biomarker for MPNST when compared with its close morphologic mimic, such as synovial sarcoma; therefore, immunohistochemical staining of HMGA2 could be a useful marker to separate MPNST from synovial sarcoma. ${ }^{4,7,23}$

\section{EGFR, p16, Neurofibromin and $\mathrm{K}_{\mathrm{i}}-\mathbf{6 7}$}

Pekmezci et al have evaluated several possible useful biomarkers for the differential diagnosis of MPNST and cellular schwannoma and concluded that these 4 biomarkers had promising use: epidermal growth factor receptor (EGFR), $\mathrm{K}_{\mathrm{i}}-67$, p16 and neurofibromin. $^{5}$
Epidermal growth factor receptor is considered an important component in the pathogenesis of MPNST. ${ }^{5}$ Pekmezci et al have shown that the expression of EGFR is exclusive of the MPNST in comparison with cellular schwannoma (31\% and $0 \%$, respectively). Furthermore, other authors had previously showed a lack of EGFR expression in schwannomas, in a general way. ${ }^{5}$

They show that there is a substantial loss of neurofibromin (the neurofibromatosis type 1 protein product) in almost all MPNST, except for few low-grade cases, while it is retained in other spindle-cell tumors. ${ }^{5}$

The same authors also observed a significant loss of expression of p16 in MPNST (73\%) against a total preservation in cellular schwannoma. ${ }^{5}$ The biomarker p16 is typically expressed in neurofibromas, and its loss could actually point to a malignization. ${ }^{6}$ The amplified expression of EGFR as well as the loss of expression of p16 and neurofibromin can help with the differential diagnosis of MPNST. ${ }^{5}$

Lastly, Pekmezci et al observed that in cellular schwannoma slices demonstrating variable labeling with focal stained areas, MPNST showed a diffuse expression. Setting a sensitivity of $87 \%$ and a specificity of $96 \%$ for $\mathrm{K}_{\mathrm{i}}-67 .^{5}$ The $\mathrm{K}_{\mathrm{i}}-67$ usage was also cited by Rodriguez et al. ${ }^{5,6}$ Actually, some authors are already using the $\mathrm{K}_{\mathrm{i}}-67$ expression in addition to the World Health Organization (WHO) classification of tumors of soft tissue and bone as a criterium to denote malignancy in perineuriomas. ${ }^{25,26}$

\section{p57NTR and SOX2: still an Obscure Area}

Pekmezci et al highlight SOX2 and p57NTR, two neural stemcell proteins, as promising biomarkers: p57NTR has been found more often in MPNSTs than in schwannomas and healthy tissue, but when comparing their conclusions with those of other authors, we found that there is still controversy in the literature. On the other hand, SOX2 has been shown in their study as a marker for both MPNSTs and schwannomas, while lacking expression in normal peripheral nerve tissue. However, further studies are needed for a better understanding of its role in peripheral nerve tissue tumors. ${ }^{5}$

\section{Conclusions}

The classical markers, such as S100 and CD34, are still important in the differentiation between schwannomas, neurofibromas and MPNST. However, there are some new more specific biomarkers that can help with a challenging diagnosis: Sox10, CD56, PGP 9.5 and nestin can assist in the differentiation, in the intracranial space or in the GI tract, between schwannomas and neurofibromas, and some other local possible tumors as well as benign peripheral nerve sheath tumors and MPNSTs. Calretinin is a good choice for distinguishing schwannomas from neurofibromas. Transducin-like enhancer of split 1 and HMGA2 seem to be promising alternatives for differentiating MPNSTs from sarcomas (for example, synovial sarcoma); nestin, EGFR, $\mathrm{p} 16$ and $\mathrm{K}_{\mathrm{i}}-67$ can possibly help to differentiate MPNSTs from cellular schwannomas, and neurofibromin can help to distinguish MPNSTs from neurofibromas. 
Furthermore, some markers presented here may have more utilities other than just diagnosing. The marker AXL can be used as a burden marker for MPNST as well as for the plexiform, nodular and dermal subtypes of neurofibromas. Lastly, podoplanin can help the physician to analyze the invasion of adjacent tissues by MPNSTs.

As it stands, there is a lack of specific biomarkers for peripheral nerve tumors. However, some new promising biomarkers have been coming to light, that require further studies and evidences for their applicability to be better classified.

\section{Financial and Material Support}

We did not receive any financial and/or material support from any granting organization or specific funding.

Conflicts of Interest

The authors of the current paper report no conflicts of interest concerning the materials or methods used in this study, or the finding described in this paper.

\section{References}

1 Fine SW, McClain SA, Li M. Immunohistochemical staining for calretinin is useful for differentiating schwannomas from neurofibromas. Am J Clin Pathol 2004;122(04):552-559

2 Shivane A, Parkinson DB, Ammoun S, Hanemann CO. Expression of c-Jun and Sox-2 in human schwannomas and traumatic neuromas. Histopathology 2013;62(04):651-656

3 Le LQ, Liu C, Shipman T, Chen Z, Suter U, Parada LF. Susceptible stages in Schwann cells for NF1-associated plexiform neurofibroma development. Cancer Res 2011;71(13):4686-4695

4 Thway K, Fisher C. Malignant peripheral nerve sheath tumor: pathology and genetics. Ann Diagn Pathol 2014;18(02):109-116

5 Pekmezci M, Reuss DE, Hirbe AC, et al. Morphologic and immunohistochemical features of malignant peripheral nerve sheath tumors and cellular schwannomas. Mod Pathol 2015;28(02):187-200

6 Rodriguez FJ, Folpe AL, Giannini C, Perry A. Pathology of peripheral nerve sheath tumors: diagnostic overview and update on selected diagnostic problems. Acta Neuropathol 2012;123(03):295-319

7 Guo A, Liu A, Wei L, Song X. Malignant peripheral nerve sheath tumors: differentiation patterns and immunohistochemical features - a mini-review and our new findings. J Cancer 2012;3:303-309

8 Naber U, Friedrich RE, Glatzel M, Mautner VF, Hagel C. Podoplanin and CD34 in peripheral nerve sheath tumours: focus on neurofibromatosis 1-associated atypical neurofibroma. J Neurooncol 2011;103(02):239-245
9 Nonaka D, Chiriboga L, Rubin BP. Sox10: a pan-schwannian and melanocytic marker. Am J Surg Pathol 2008;32(09):1291-1298

10 Miettinen M, McCue PA, Sarlomo-Rikala M, et al. Sox10-a marker for not only schwannian and melanocytic neoplasms but also myoepithelial cell tumors of soft tissue: a systematic analysis of 5134 tumors. Am J Surg Pathol 2015;39(06):826-835

11 Miettinen M. Immunohistochemistry of soft tissue tumours - review with emphasis on 10 markers. Histopathology 2014;64(01):101-118

12 Skovronsky DM, Oberholtzer JC. Pathologic classification of peripheral nerve tumors. Neurosurg Clin N Am 2004;15(02):157-166

13 Schulz A, Zoch A, Morrison H. A neuronal function of the tumor suppressor protein merlin. Acta Neuropathol Commun 2014;2 (01):82

14 Caltabiano R, Magro G, Polizzi A, et al. A mosaic pattern of INI1/ SMARCB1 protein expression distinguishes Schwannomatosis and NF2-associated peripheral schwannomas from solitary peripheral schwannomas and NF2-associated vestibular schwannomas. Childs Nerv Syst 2017;33(06):933-940

15 Karamchandani JR, Nielsen TO, van de Rijn M, West RB. Sox10 and $\mathrm{S} 100$ in the diagnosis of soft-tissue neoplasms. Appl Immunohistochem Mol Morphol 2012;20(05):445-450

16 Zhang HY, Yang GH, Chen HJ, et al. Clinicopathological, immunohistochemical, and ultrastructural study of 13 cases of melanotic schwannoma. Chin Med J (Engl) 2005;118(17):1451-1461

17 Kleinschmidt-DeMasters BK, Tihan T, Rodriguez F. Diagnostic Pathology: Neuropathology. Elsevier Health Sciences 2016:528-545

18 Jett K, Friedman JM. Clinical and genetic aspects of neurofibromatosis 1. Genet Med 2010;12(01):1-11

19 Johansson G, Peng PC, Huang PY, et al. Soluble AXL: a possible circulating biomarker for neurofibromatosis type 1 related tumor burden. PLoS One 2014;9(12):e115916

20 Weiss SW, Goldblum JR, Folpe AL. Enzinger and Weiss' soft tissue tumors. Philadelphia: Saunders/Elsevier; 2014

21 Henderson SR, Guiliano D, Presneau N, et al. A molecular map of mesenchymal tumors. Genome Biol 2005;6(09):R76

22 Ferner RE. Neurofibromatosis 1 and neurofibromatosis 2: a twenty first century perspective. Lancet Neurol 2007;6(04):340-351

23 Hui $\mathrm{P}$, Li N, Johnson $\mathrm{C}$, et al. HMGA proteins in malignant peripheral nerve sheath tumor and synovial sarcoma: preferential expression of HMGA2 in malignant peripheral nerve sheath tumor. Mod Pathol 2005;18(11):1519-1526

24 Shimada S, Tsuzuki T, Kuroda M, et al. Nestin expression as a new marker in malignant peripheral nerve sheath tumors. Pathol Int 2007;57(02):60-67

25 Hayashi T, Hirose T, Nishimura Y, Fukuoka J, Kishikawa M. Hybrid schwannoma/perineurioma of the spinal nerve: multifocal occurrence, and recurrence as an intraneural perineurioma. Pathol Int 2013;63(07):368-373

26 Fletcher CDM, Unni KK, Martens F. World Health Organization classification of tumors. Pathology and Genetics of Tumors of Soft Tissue and Bone. IARC Press; 2002 